\title{
REAÇÕES ALDÓLICAS ASSIMÉTRICAS CATALÍTICAS
}

Ivan R. Corrêa Jr. e Ronaldo A. Pilli*

Instituto de Química, Universidade Estadual de Campinas, CP 6154, 13083-970 Campinas - SP

Nesta revisão, publicada no vol.26, n. 4, p. 531-541, ocorreram problemas em algumas Figuras e Esquemas, devido a uma falha na fase final de editoração do texto. Abaixo segue a versão correta das Figuras e dos Esquemas.
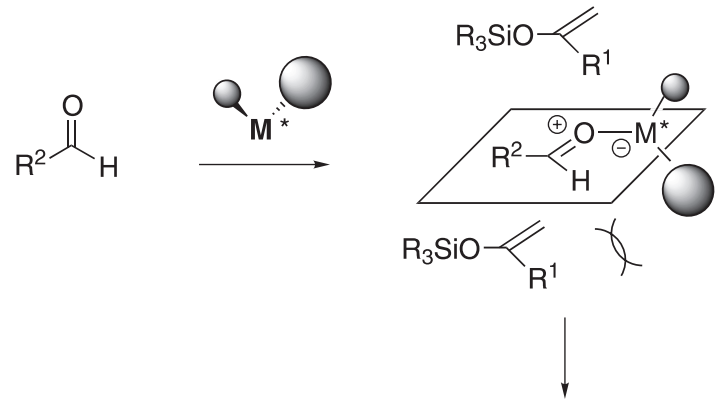

OSiR

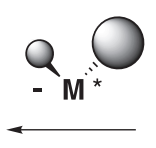

Seletividade Sin<smiles>[R5]C=C[O+]=CC(=O)OC</smiles>

Seletividade Anti<smiles>CCOC(=COCc1ccccc1)CC</smiles>

(E) $-\mathrm{PhCH}=\mathrm{CH}, \mathrm{C}_{2} \mathrm{H}_{5}$

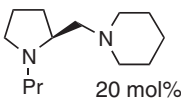

$\mathrm{Sn}(\mathrm{OTf})_{2}$ $\underset{\mathrm{CH}_{2} \mathrm{Cl}_{2},-78^{\circ} \mathrm{C}}{\stackrel{\left({ }^{\mathrm{B} u}\right)_{2} \mathrm{Sn}(\mathrm{OAC})_{2}}{\longrightarrow}}$<smiles>[R]C(OC)C([OH2+])C(=O)SCC</smiles>

rend. $46-86 \%$ sin:anti 88:12 a 93:7 $\%$ ee (sin) 82-94

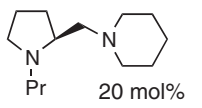

$\mathrm{Sn}(\mathrm{OTf})_{2}$

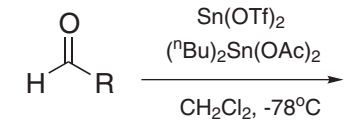<smiles>[R]C(OC)C(OCC)C(=O)SCC</smiles>

rend. $72-88 \%$ sin:anti $91: 9$ a $99: 1$ $\%$ ee $(\sin )$ 95-98

Figura 1

Esquema 4
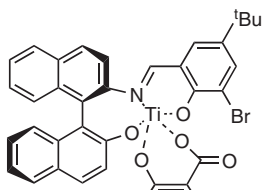

1)
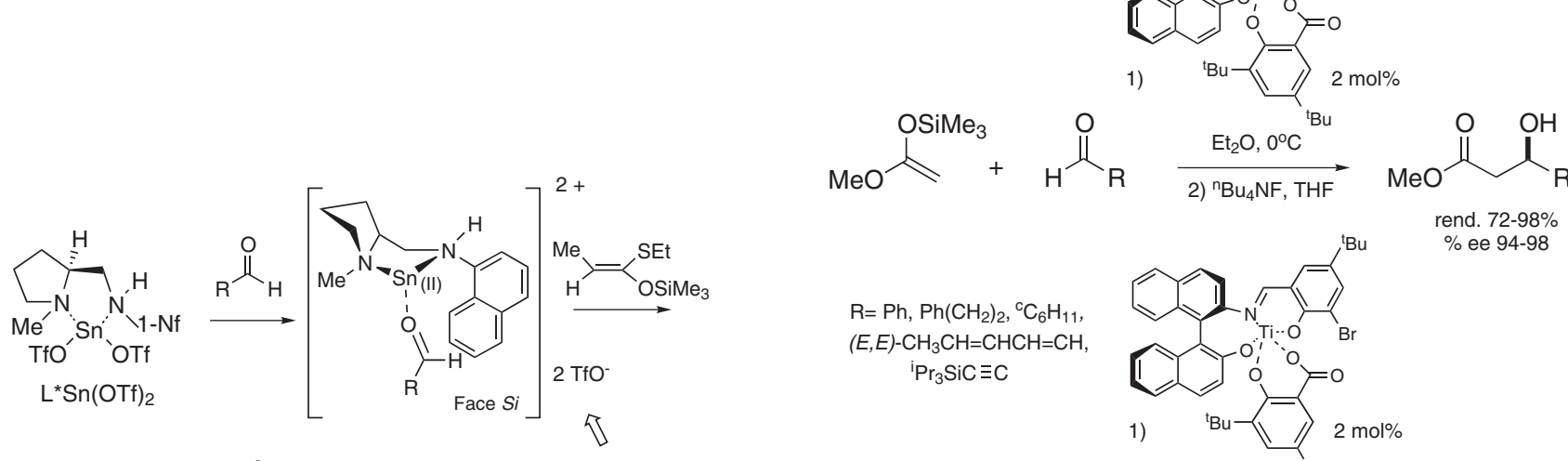

$\%$ ee $94-98$

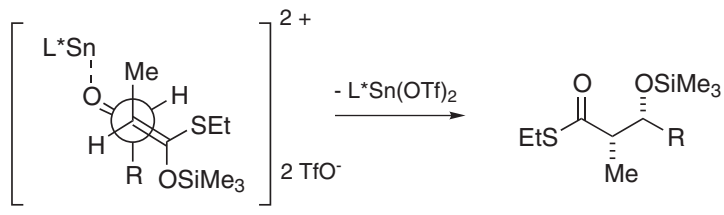

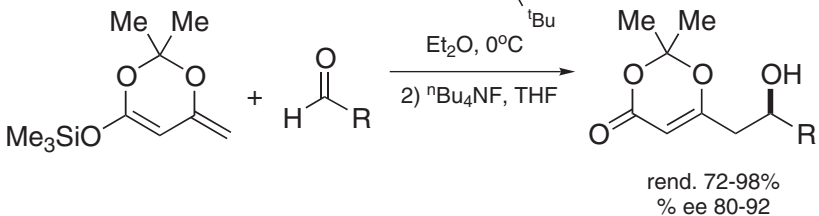




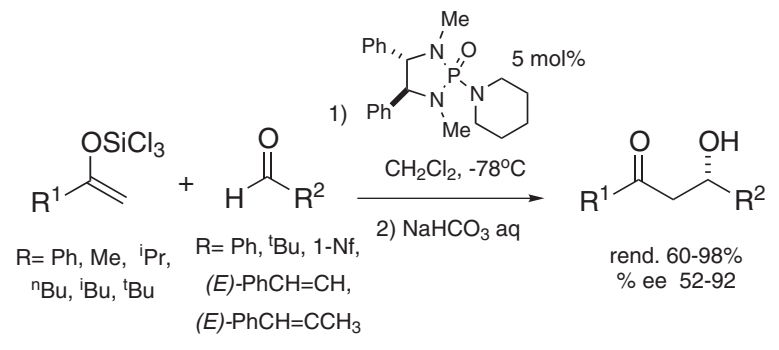

Esquema 21

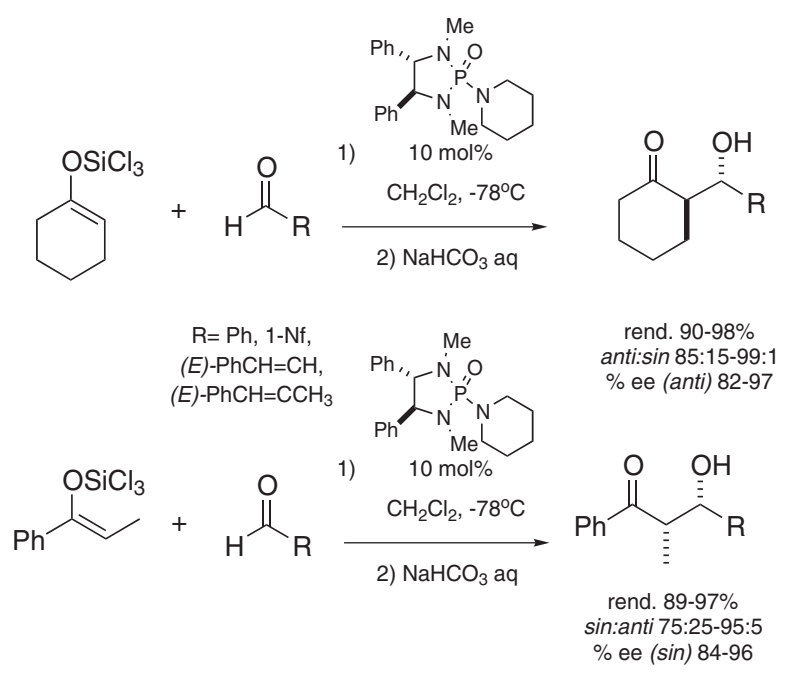

Esquema 22

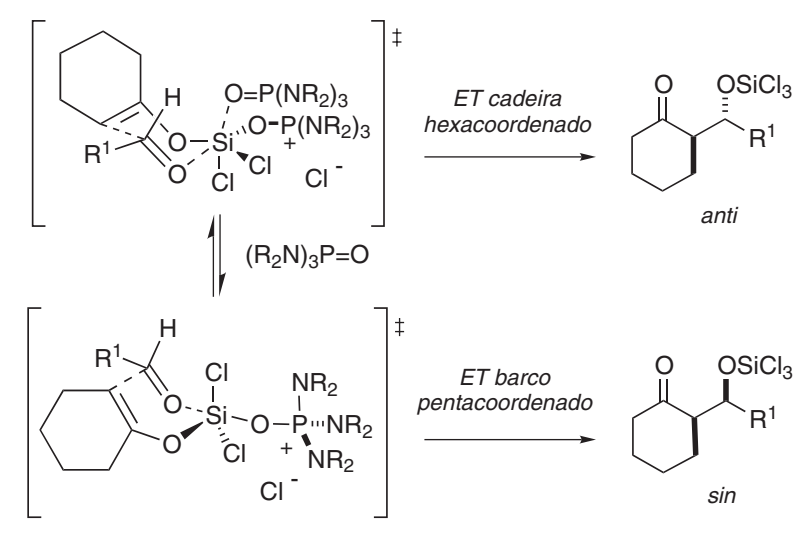

Figura 9

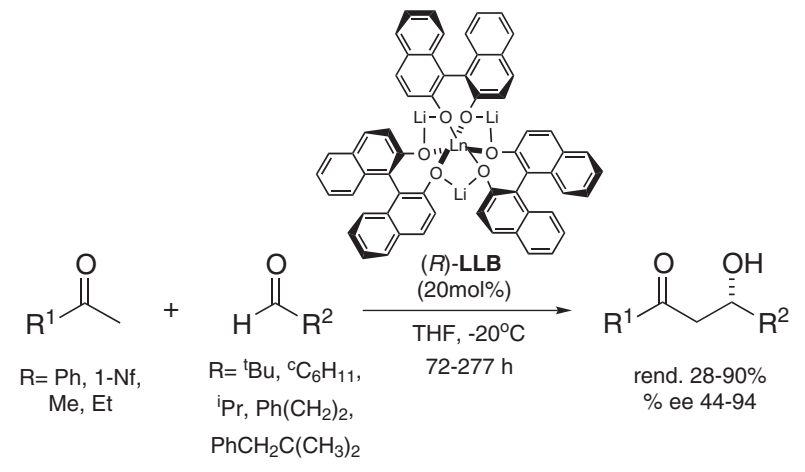

Esquema 23

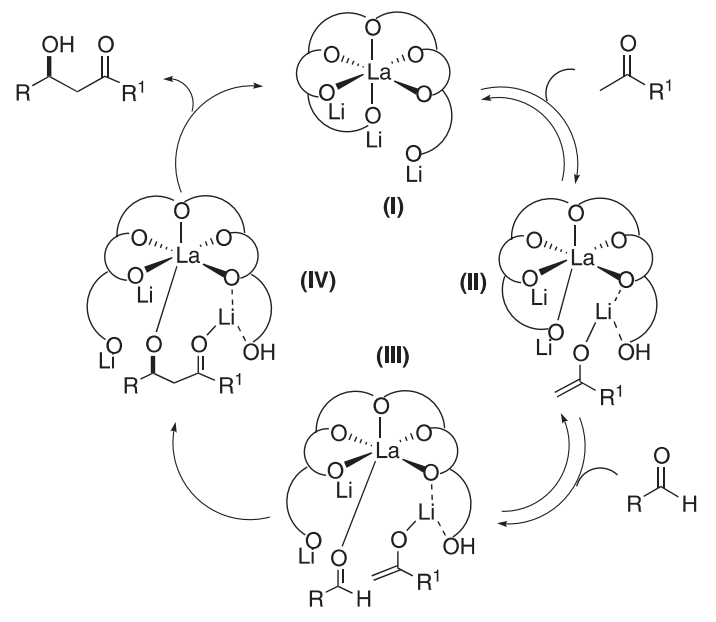

Figura 11

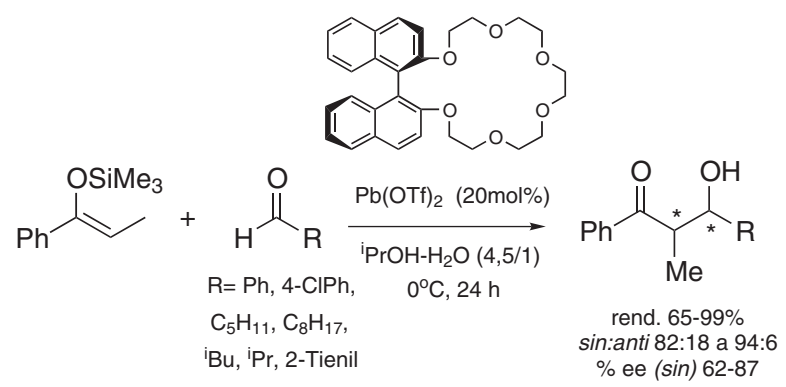

